\title{
Relações entre variáveis nas análises de sementes de espécies florestais nativas do Rio Grande do Sul
}

\author{
Relationship among seed analysis variables of native species of Rio Grande do Sul State, Brazil
}

\author{
Alessandro Dal'Col Lúcio ${ }^{\mathrm{I}^{*}}$ Fabiano de Oliveira Fortes ${ }^{\mathrm{II}}$ Leandro Homrich Lorentz ${ }^{\mathrm{II}}$ \\ Sidinei José Lopes ${ }^{\mathrm{I}}$ Lindolfo Storck ${ }^{\mathrm{I}}$
}

\section{RESUMO}

Este trabalho teve por objetivos identificar as variáveis avaliadas nas análises de sementes que mais influenciaram na qualidade dos lotes armazenados de sementes de espécies florestais nativas do Sul do Brasil e verificar suas relações com a percentagem de germinação de plântulas normais. As informações relacionadas às análises de sementes de oito espécies florestais foram obtidas do banco de dados do laboratório de análise de sementes florestais da Fundação Estadual de Pesquisa Agropecuária do Rio Grande do Sul. Realizou-se a análise de trilha, para verificar a existência da relação entre pureza, peso de mil sementes, umidade, percentagens de germinação de plântulas normais e anormais $e$ percentagens de sementes firmes e mortas, avaliadas nos lotes armazenados no laboratório. A percentagem de germinação de plântulas normais possui maiores relações significativas com as variáveis peso de mil sementes, umidade das sementes e percentagem de sementes mortas.

Palavras-chave: análise de trilha; correlação; armazenamento de sementes; controle de qualidade; análise multivariada.

\section{ABSTRACT}

This research was aimed at determining which variables of seed analysis affects most stored seed quality of native species of Rio Grande do Sul State and verify its relationship with germination percentage of normal seeds. Data related to seed analysis of eight forest species were obtained from the State Foundation for Agricultural Research and a path coefficient analysis was conducted to obtain the relationship among purity of the lots, weight of a thousand seeds, humidity, percentage of normal and anormalous seedlings, firm and dead seeds obtained from batches stored in the laboratory. The percentage of normal seedling presented higher significant relationships with the variables weight of a thousand seeds, humidity and percentage of dead seeds.

Key words: path analysis; correlation; storage of seeds; quality control; multivariate analysis.

\section{INTRODUÇÃO}

O teste de germinação é empregado rotineiramente para avaliar a qualidade de sementes, sendo que a percentagem de plântulas normais obtidas nesses testes representa o máximo que a amostra pode oferecer, em condições ótimas, artificiais e padronizadas para cada espécie avaliada (BRASIL, 1992 e MACHADO, 2002). A germinação de sementes, em testes de laboratório, é a emergência das estruturas essenciais do embrião, demonstrando sua aptidão para produzir planta normal sob condições favoráveis de campo, conforme definição em BRASIL (1992). A dificuldade de se avaliar qualquer componente da qualidade de um lote de sementes está intimamente relacionada aos problemas da amostragem, tal como o número de repetições (VIEIRA \& CARVALHO, 1994).

De acordo com as Regras para Análise de Sementes - RAS (BRASIL, 1992), as sementes são classificadas como: a) plântulas normais são aquelas que mostram potencial para continuar seu desenvolvimento e dar origem a plantas normais; b) plântulas anormais são aquelas que não mostram potencial para continuar seu desenvolvimento e dar

\footnotetext{
'Departamento de Fitotecnia, Centro de Ciências Rurais (CCR), Universidade Federal de Santa Maria (UFSM), Campus Universitário, Camobi, 97105-900, Santa Maria, RS, Brasil. E-mail: adlucio@smail.ufsm.br. *Autor para correspondência.

II CCR, UFSM, Santa Maria, RS, Brasil.
} 
origem a plântulas normais; c) sementes duras são as que permanecem sem absorver água por um período mais longo que o normal e se apresentam, no final do teste, com aspecto de sementes recém-colocadas no substrato; d) sementes dormentes são as que, embora aparentemente viáveis, não germinam mesmo quando colocadas nas condições especificadas para a espécie em teste; e) sementes mortas são as que, ao final do teste, não germinaram, não estão duras, nem dormentes, e, geralmente, apresentam-se amolecidas ou atacadas por microorganismos. Além dessas variáveis, a percentagem de pureza, o peso de mil sementes e a percentagem de umidade são avaliadas nas análises de sementes de espécies florestais, com intuito de determinar a qualidade física de um lote armazenado, e apresentam grande variabilidade nas repostas (MACHADO, 2002).

Ao realizar as análises de sementes de uma determinada espécie florestal, há a necessidade de se conhecer a interferência do tempo e das condições de armazenamento sobre a qualidade das sementes armazenadas e no seu potencial de produção de mudas. A germinação de sementes, em testes de laboratório, é a emergência das estruturas essenciais do embrião, demonstrando sua aptidão para produzir planta normal sob condições favoráveis de campo, conforme definição em BRASIL (1992). A dificuldade de se avaliar qualquer componente da qualidade de um lote de sementes está intimamente relacionada aos problemas da amostragem e ao número de repetições, entre outros (VIEIRA\& CARVALHO, 1994).

Em um processo de germinação de sementes, principalmente de espécies florestais, há um problema a ser superado em relação à dormência das sementes, pois, segundo KRAMER \& KOZLOWSKI (1972) e FLORIANO (2004), sementes de cerca de um terço das espécies germinam imediatamente em condições favoráveis, mas as demais apresentam algum grau de dormência. FOWLER \& BINCHETTI (2000) citam que, entre os processos mais comuns para superação da dormência de sementes, estão: escarificação química, escarificação mecânica, estratificação fria e quente-fria, choque térmico, exposição à luz intensa, imersão em água quente e embebição em água fria.

O germoplasma é o elemento dos recursos genéticos que maneja a variabilidade genética entre e dentro das espécies (GOEDERT et al., 2002), com fins de utilização na pesquisa, visando ao melhoramento genético, inclusive à biotecnologia. No entanto, os produtores compram sementes ou mudas de espécies florestais sem ter garantia da qualidade e do poder germinativo do lote. Assim, torna-se imprescindível conhecer as características das espécies florestais cultivadas e comercializadas, tanto das nativas quanto das exóticas de uma determinada região.

O estudo das correlações entre caracteres tem aplicações em praticamente todos os campos de pesquisa. A correlação linear simples permite apenas avaliar a magnitude e o sentido da associação entre dois caracteres, sem fornecer informações necessárias relativas aos efeitos diretos e indiretos de um grupo de caracteres em relação a uma variável dependente de maior importância (CRUZ, 2001). A análise de trilha permite o estudo dos efeitos de algumas variáveis independentes sobre uma variável básica, cujas estimativas são obtidas por meio de equações de regressão, em que as variáveis são primeiramente padronizadas, conforme apresentado por VENCOVSKY \& BARRIGA (1992) e CRUZ (2001). Esta análise se baseia em um sistema de equações lineares previamente padronizadas, na qual a presença de alta correlação entre as variáveis independentes (multicolinearidade) pode comprometer as estimativas dos coeficientes (efeitos diretos e indiretos), sendo necessário, nestes casos, um diagnóstico do grau de colinearidade. Esta diagnose, entre as variáveis independentes, é realizada pela razão entre o maior e o menor autovalor, obtidos a partir da matriz de correlações (MONTGOMERY \& PECK, 1981), que deve resultar em um valor menor do que 100 para ser considerado como multicolinearidade fraca, conforme classificação proposta por CRUZ (2001). É necessário detectar quais são as variáveis que favorecem a presença desse efeito e eliminá-las da análise estatística ou realizar a análise de trilha sob efeito da multicolinearidade que, de acordo com CARVALHO et al. (1999), pode trazer resultados sem interpretação prática dos efeitos diretos e indiretos obtidos entre as variáveis em estudo.

A análise de trilha pode ter seu uso extrapolado para outras áreas de investigação, além do melhoramento genético, mostrando o tipo e o grau de relação entre variáveis e fornecendo condições de melhor planejamento e condução do experimento. Além disso, pode também ser aplicada como método de identificação das variáveis menos explicativas do comportamento da variável dependente principal e, assim, eliminá-las do estudo, como utilizado por NASCIMENTO FILHO et al. (1993) e LÚCIO (1999).

Desta forma, o presente trabalho teve por objetivos identificar as variáveis das análises de sementes que mais merecem atenção no armazenamento das sementes de espécies florestais nativas do Estado do Rio Grande do Sul e verificar suas relações com a percentagem de germinação de plântulas normais. 


\section{MATERIAL E MÉTODOS}

As espécies estudadas foram Allophylus edulis (St.Hil.) Radlk., Apuleia leiocarpa (Vogel) JF Macbr., Cassia leptophylla Vogel, Cedrela fissilis Vell., Enterolobium contortisiliquum (Vell.) Morong, Lafoensia pacari Saint-Hilaire, Peltophorum dubium (Sprengel) Taubert e o gênero Schinus sp. L., descritas por LORENZI (1992) como nativas para o Estado do Rio Grande do Sul, onde FOWLER \& BINCHETTI (2000) descrevem tratamentos para superar a dormência das sementes dessas espécies. No laboratório de análise de sementes florestais da Fundação Estadual de Pesquisa Agropecuária do Rio Grande do Sul, localizado no Centro de Pesquisas Florestais e Conservação do Solo, no município de Santa Maria RS, são realizadas as análises de sementes florestais, bem como o armazenamento dos lotes compostos pelas espécies descritas, em sacos de papel, a uma temperatura entre 12 e $14^{\circ} \mathrm{C}$ e umidade entre 10 e $15 \%$, sem nenhum tratamento prévio na formação e manutenção dos lotes, mas com quebra de dormência para análise de germinação. Assim, a partir dos laudos das 157 análises de sementes das espécies florestais nativas armazenadas, realizadas no período de janeiro de 1997 a fevereiro de 2003, independentes da procedência e de tempo de armazenamento do lote de sementes, coletaram-se as seguintes informações: percentagem da pureza das sementes (PUR), peso de mil sementes (PMS) em gramas, umidade do lote (U\%), percentagem de germinação de plântulas normais (PN), percentagem de plântulas anormais (PA), percentagem de sementes firmes (SF) e percentagem de sementes mortas (SM), conforme definições da RAS (BRASIL, 1992).

Obteve-se as estimativas dos coeficientes de correlação linear de Pearson entre todos os pares de variáveis e, após isso, realizou-se o diagnóstico de multicolinearidade, mantendo-se no estudo as variáveis que proporcionaram multicolinearidade fraca, ou seja, o número de condições (NC) menor do que 100, conforme critério apresentado por CRUZ (2001) e CARVALHO et al. (2002). A seguir, os coeficientes de correlação de Pearson foram desdobrados em efeitos diretos e indiretos, conforme descrito em CRUZ \& REGAZZI (1994), adotando a variável percentagem de germinação de plântulas normais (PN) como a variável dependente principal e as demais, a partir de um grupo de variáveis que não apresentaram multicolinearidade entre si, como independentes. Para a realização das análises estatísticas, utilizou-se o programa GENES (CRUZ, 2001), aplicando o teste “t” a 5\% de probabilidade de erro, para testar significância dos coeficientes de correlação.

\section{RESULTADOS E DISCUSSÃO}

As estimativas dos coeficientes de correlação linear (Tabelas 1 e 2) apresentaram comportamento diferenciado entre as espécies florestais estudadas, em relação às suas significâncias, variando de oito correlações significativas para a $\boldsymbol{A}$. leiocarpa a apenas uma no caso da A. edulis, $\boldsymbol{C}$. leptophylla e $\boldsymbol{E}$. contortisiliquum, indicando que as variáveis relacionam-se de forma diferente para cada espécie. Este comportamento fica evidenciado na percentagem de germinação de plântulas normais (PN) como uma variável principal, em que se verifica que a correlação linear desta com as demais é influenciada pela espécie. Assim, pode-se prever que o preparo dos lotes de sementes para o armazenamento não deve ser realizado com o mesmo procedimento para todas as espécies florestais.

As estimativas dos coeficientes de correlação de Pearson comprovam que algumas relações de interesse são significativamente negativas, como pureza (PUR) e peso de mil sementes (PMS) de A. edulis (Tabela 1). Este comportamento mostra que, para aumentar a pureza em um lote desta espécie, devese melhorar o processo de beneficiamento e preparo dos lotes, com a eliminação adequada das impurezas existentes, das sementes maiores e das que apresentam características de mortas. Este procedimento irá reduzir o PMS que, por ter uma correlação negativa com PN, irá proporcionar maior formação de plântulas normais. Já, no caso do coeficiente de correlação significativo e positivo para Schinus sp. (Tabela 2), o aumento no PMS aumenta a PUR. Assim, este processo de preparo do lote fica mais facilitado pela melhor separação das impurezas nos lotes, já que, comparando com A. edulis, as sementes de $\boldsymbol{S c h i n u s ~ s p . ~ s a ̃ o ~ m a i o r e s ~ ( L O R E N Z I , ~}$ 1992), o que, provavelmente, proporcionou o comportamento contrário entre PUR e PMS apresentado por essas duas espécies.

Para as relações entre todas as variáveis com a percentagem de plântulas normais $(\mathrm{PN})$, que é a variável de maior importância, algumas correlações mostraram-se óbvias: com a percentagem de sementes mortas (SM) e com a percentagem de sementes firmes (SF), apresentando coeficientes sempre negativos ou não-significativos. Uma correlação linear, neste caso, entre PMS e PN na A. leiocarpa (Tabela 1), positiva e significativa, mostra que, nesta espécie, ao se escolher sementes maiores para comporem o lote, aumenta-se a percentagem de germinação de plântulas normais, prática esta de certa facilidade a ser adotada quando do preparo de um lote de sementes a ser armazenado.

Com a verificação da multicolinearidade, algumas variáveis foram retiradas da análise de trilha, 
Tabela 1 - Coeficiente de correlação linear de Pearson entre pureza (PUR), peso de mil sementes (PMS), umidade (U\%), percentagem de germinação das plântulas normais (PN), percentagem de sementes firmes (SF), percentagem de plântulas anormais (PA) e percentagem de sementes mortas (SM) e número de análises realizadas (N) nos lotes de sementes de espécies florestais nativas do Rio Grande do Sul. Santa Maria - RS, 2005.

\begin{tabular}{|c|c|c|c|c|c|}
\hline & & \multicolumn{4}{|c|}{ Espécies florestais } \\
\hline & & $\begin{array}{l}\text { Allophylus edulis } \\
\qquad(\mathrm{N}=12)\end{array}$ & $\begin{array}{c}\text { Apuleia leiocarpa } \\
\qquad(\mathrm{N}=18)\end{array}$ & $\begin{array}{c}\text { Cassia leptophylla } \\
(\mathrm{N}=20)\end{array}$ & $\begin{array}{l}\text { Cedrela fissilis } \\
\quad(\mathrm{N}=20)\end{array}$ \\
\hline \multirow[t]{6}{*}{ PUR $x$} & PMS & $-0,7724^{*}$ & $-0,1747$ & $-0,4339$ & 0,1316 \\
\hline & U\% & $-0,1731$ & $-0,1114$ & 0,2078 & 0,1424 \\
\hline & PN & 0,4524 & $-0,3223$ & 0,1313 & $0,6141^{*}$ \\
\hline & SF & $-0,2664$ & 0,2470 & 0,1640 & 0,2640 \\
\hline & PA & 0,3252 & 0,1795 & 0,0000 & 0,0071 \\
\hline & SM & 0,1562 & 0,3145 & $-0,1492$ & $-0,6401 *$ \\
\hline \multirow[t]{5}{*}{ PMS $x$} & $\mathrm{U} \%$ & $-0,2463$ & $0,8564 *$ & 0,0268 & 0,4781 \\
\hline & PN & $-0,5589$ & $0,7818^{*}$ & 0,0322 & 0,0386 \\
\hline & SF & 0,2432 & $-0,3148$ & $-0,1643$ & 0,0118 \\
\hline & PA & $-0,3301$ & 0,0000 & 0,0000 & 0,0739 \\
\hline & SM & $-0,0287$ & $-0,7820^{*}$ & $-0,0156$ & $-0,0406$ \\
\hline \multirow[t]{4}{*}{$\mathrm{U} \% \mathrm{x}$} & PN & 0,5124 & $0,8410^{*}$ & 0,2126 & 0,2071 \\
\hline & SF & $-0,5253$ & $-0,6861$ & $-0,2278$ & 0,0984 \\
\hline & PA & 0,0000 & 0,0000 & 0,0000 & $-0,1108$ \\
\hline & SM & 0,5577 & $-0,8376 *$ & $-0,1873$ & $-0,2156$ \\
\hline \multirow[t]{3}{*}{$\mathrm{PN} x$} & SF & $-0,3521$ & $-0,5407^{*}$ & $-0,1295$ & 0,0833 \\
\hline & PA & 0,0124 & $-0,4089$ & 0,0000 & $-0,3511$ \\
\hline & SM & $-0,3308$ & $-0,9953 *$ & $-0,9948 *$ & $-0,9912 *$ \\
\hline \multirow[t]{2}{*}{ SF $x$} & PA & $-0,0325$ & $0,8893^{*}$ & 0,0000 & $-0,1332$ \\
\hline & SM & $-0,4066$ & 0,4617 & 0,0275 & $-0,2138$ \\
\hline PA $x$ & SM & 0,0905 & 0,3202 & 0,0000 & 0,3505 \\
\hline
\end{tabular}

* significativo a 5\% de probabilidade de erro.

como pode ser verificado nas tabelas 3 e 4 . Para todas as espécies estudadas, a variável percentagem de plântulas anormais (PA) foi retirada, sendo seguida pela SF com retirada em $75 \%$ das espécies, da SM com $62,5 \%$ das espécies e da U\% com 12,5\%. Este comportamento das três primeiras variáveis explica-se pelo fato de que, ao se preparar um lote de sementes para armazenamento, há o cuidado de eliminar ao máximo as sementes que apresentam características indesejáveis, tais como: rachaduras, coloração inespecífica e sementes quebradas. Assim, pela própria recomendação de preparo de lotes de sementes, há uma relação direta dessas variáveis com a percentagem de germinação de plântulas normais, favorecendo assim a presença da multicolinearidade. Em relação à multicolinearidade existente entre PN e SF, deve-se ainda comentar que, para o processo de análise da germinação das sementes, houve tratamento para superação da dormência, o que favoreceu as correlações entre essas variáveis, que apresentaram estimativas negativas ou nãosignificativas para todas as espécies avaliadas.

Comprovou-se com a análise de trilha que a importância relativa das variáveis analisadas nos laudos difere com a espécie, quando relacionada à percentagem de germinação de plântulas normais. Para a espécie $\boldsymbol{A}$. edulis, na variável SF, tanto o coeficiente de correlação $(r=-0,3521)$ (Tabela 1) quanto o efeito direto $(-0,499)$ (Tabela 3), e, para variável SM, tanto o coeficiente de correlação $(r=-0,3308)$ (Tabela 1 ) quanto o efeito direto $(-0,546)$ (Tabela 3$)$, sobre a percentagem de germinação das plântulas normais, foram negativos, indicando que, quanto menores estas percentagens, maior será a percentagem de plantas germinadas. $\mathrm{Na}$ interpretação dos resultados obtidos nas decomposições do coeficiente de correlação linear de Pearson em efeitos direto e indireto, deve-se considerar 
Tabela 2 - Coeficiente de correlação linear de Pearson entre pureza (PUR), peso de mil sementes (PMS), umidade (U\%), percentagem de germinação das plântulas normais (PN), percentagem de sementes firmes (SF), percentagem de plântulas anormais (PA) e percentagem de sementes mortas (SM) e número de análises realizadas (N) nos lotes de sementes de espécies florestais nativas do Rio Grande do Sul. Santa Maria - RS, 2005.

\begin{tabular}{|c|c|c|c|c|c|}
\hline & & \multicolumn{4}{|c|}{ Espécies florestais } \\
\hline & & $\begin{array}{c}\text { Enterolobium } \\
\text { contortisiliquum }(\mathrm{N}=28)\end{array}$ & $\begin{array}{l}\text { Lafoensia pacari } \\
\qquad(\mathrm{N}=17)\end{array}$ & $\begin{array}{l}\text { Pelthoforum dubium } \\
\qquad(\mathrm{N}=17)\end{array}$ & $\begin{array}{l}\text { Schinus } s p \\
(\mathrm{~N}=25)\end{array}$ \\
\hline \multirow[t]{6}{*}{ PUR $x$} & PMS & 0,1837 & $-0,2844$ & $-0,3918$ & $0,6328 *$ \\
\hline & $\mathrm{U} \%$ & 0,3972 & $-0,6144$ & $-0,3113$ & $-0,1706$ \\
\hline & PN & 0,1138 & $-0,3364$ & $-0,1174$ & 0,1061 \\
\hline & SF & 0,0431 & 0,0805 & 0,2868 & 0,2642 \\
\hline & PA & 0,0705 & 0,0000 & 0,2821 & 0,0000 \\
\hline & $\mathrm{SM}$ & $-0,1203$ & 0,3203 & 0,2423 & $-0,2868$ \\
\hline \multirow[t]{5}{*}{ PMS $x$} & $\mathrm{U} \%$ & 0,1404 & 0,6291 & $-0,3157$ & $-0,2818$ \\
\hline & PN & $-0,1098$ & 0,3532 & $0,9276 *$ & 0,3907 \\
\hline & SF & 0,1444 & $-0,4906^{*}$ & $0,5095 *$ & 0,5018* \\
\hline & PA & $-0,0647$ & 0,0000 & 0,2169 & 0,0000 \\
\hline & $\mathrm{SM}$ & 0,1084 & $-0,2046$ & $-0,3379$ & $-0,7203^{*}$ \\
\hline \multirow[t]{4}{*}{$\mathrm{U} \% \mathrm{x}$} & PN & 0,3838 & $-0,4958$ & $-0,1857$ & $-0,3843$ \\
\hline & SF & $-0,2161$ & 0,0648 & $-0,1468$ & $-0,0180$ \\
\hline & PA & $-0,2557$ & 0,0000 & $-0,2339$ & 0,0000 \\
\hline & $\mathrm{SM}$ & $-0,3530$ & 0,7128 & $-0,2465$ & 0,3716 \\
\hline \multirow[t]{3}{*}{$\mathrm{PN} x$} & SF & 0,0235 & $-0,2477$ & 0,2994 & $-0,2793$ \\
\hline & PA & $-0,3051$ & 0,0000 & 0,2224 & 0,0000 \\
\hline & $\mathrm{SM}$ & $-0,998 *$ & $-0,9493 *$ & $-0,9925 *$ & $-0,7291$ \\
\hline \multirow[t]{2}{*}{ SF $x$} & PA & $-0,0022$ & 0,0000 & $0,5853^{*}$ & 0,0000 \\
\hline & $\mathrm{SM}$ & $-0,0574$ & $-0,0692$ & $-0,3985$ & $-0,4535^{*}$ \\
\hline PA $x$ & SM & 0,2529 & 0,0000 & $-0,3273$ & 0,0000 \\
\hline
\end{tabular}

* significativo a 5\% de probabilidade de erro.

que, quando o coeficiente de correlação e o efeito direto forem iguais ou semelhantes, em magnitude e sinal, esta correlação direta explica a verdadeira associação existente entre as variáveis (VENCOVSKY \& BARRIGA, 1992). Se o coeficiente de correlação de Pearson for positivo, mas o efeito direto for negativo ou desprezível, a correlação será causada pelos efeitos indiretos, sendo estes considerados na análise. Com o coeficiente de correlação de Pearson desprezível e o efeito direto apresentando-se positivo e alto, os efeitos indiretos é que são responsáveis pela falta de correlação, merecendo a mesma atenção na análise. Finalmente, com a correlação de Pearson negativa e efeito direto positivo e alto, deve-se eliminar os efeitos indiretos da análise e aproveitar somente os diretos.

Nos lotes de sementes de A. leiocarpa, para uma elevada percentagem de germinação de plântulas normais, é necessário que apresentem um alto grau de umidade, ou seja, que as sementes possuam alto teor de água, sendo recomendado para aumentar a germinação deixar as sementes até oito horas em repouso dentro de recipiente com água (LORENZI, 1992) ou escarificação mecânica mais 120 horas embebidas em água (FLORIANO, 2004), para a quebra da dormência tegumentar. Este comportamento comprova-se, já que tanto o coeficiente de correlação de Pearson (Tabela 1), quanto o efeito direto (Tabela 3), apresentaram-se com mesma magnitude e sinal. Também se deve optar por sementes de maiores tamanhos ou mais pesadas; no entanto, essa situação está associada ao efeito indireto causado pela umidade das sementes. É curiosa a relação entre a pureza e a PN, pois com base na análise de trilha apresentada na tabela 3 , pode-se inferir que lotes com maior impureza favorecem a germinação. No entanto, esta informação deve ser desconsiderada, já 
Tabela 3 - Efeitos diretos e indiretos da pureza dos lotes (PUR), do peso de mil sementes (PMS), da umidade (U\%), da percentagem de plântulas anormais (PA), da percentagem de sementes firmes (SF) e da percentagem de sementes mortas (SM) sobre a percentagem de germinação das plântulas normais (PN), em espécies florestais nativas do Rio Grande do Sul. Santa Maria - RS, 2005.

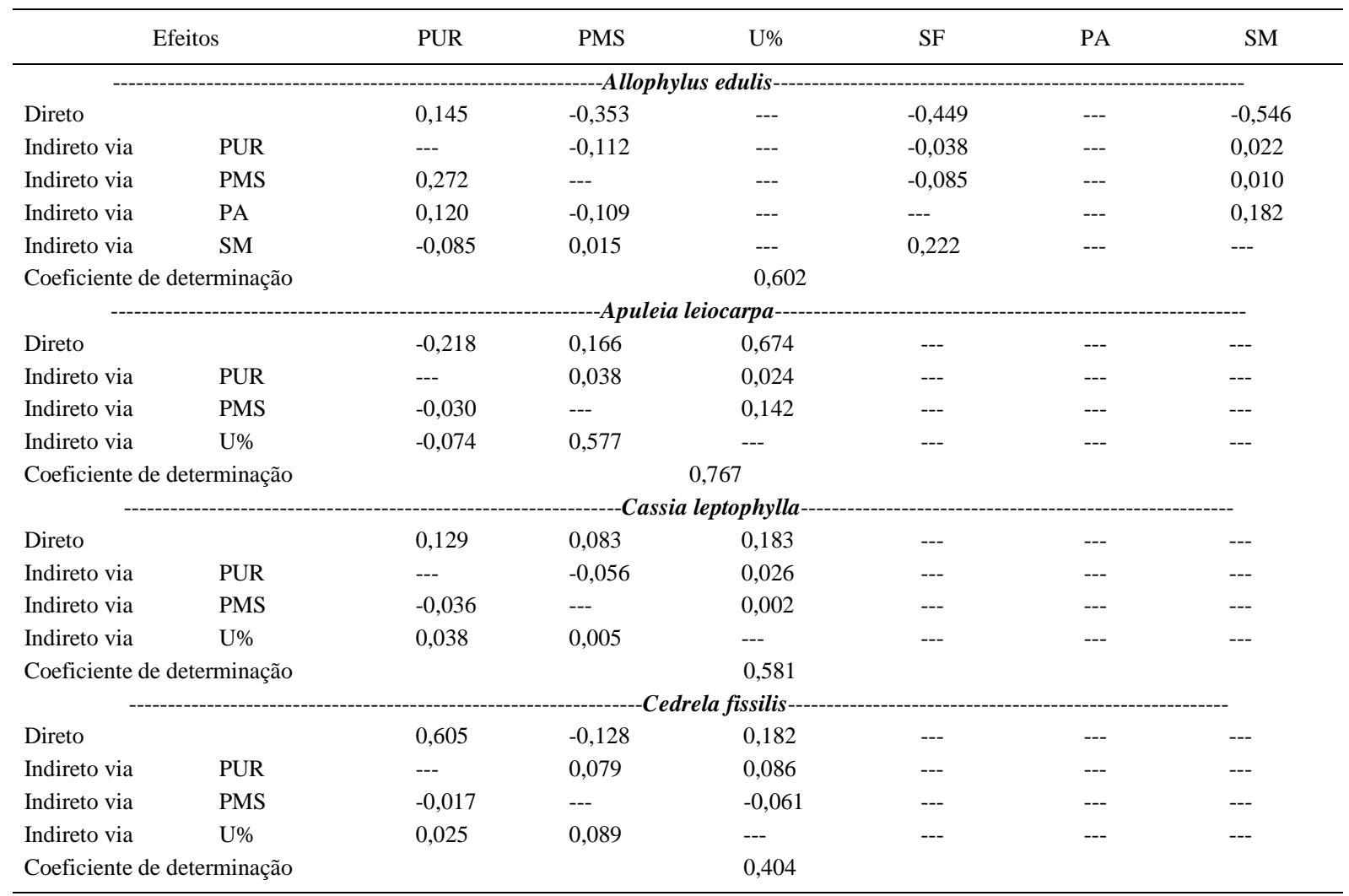

que, tanto o coeficiente de correlação entre PUR e PN, quanto o efeito direto, são baixos e não significativos.

Apesar das estimativas obtidas para os efeitos direto e indireto entre as variáveis para a $\boldsymbol{C}$. leptophylla (Tabela 3), o efeito residual apresentou-se muito alto $(0,9035)$, não sendo possível inferir com precisão aceitável sobre as relações existentes entre as variáveis em estudo. Pode-se afirmar que não foram observadas relações entre a percentagem de germinação de plântulas normais e as demais variáveis avaliadas, exceto para PMS (Tabela 1).

Para aumentar a percentagem de germinação dos lotes de sementes de $\boldsymbol{C}$. fissilis, a estratégia é melhorar a sua pureza, pois estão altamente correlacionadas, pela concordância, em magnitude e sinal do coeficiente de correlação de Pearson (0,6141), observado na tabela 1, e seu respectivo efeito direto $(0,605)$, observado na tabela 3. Uma importância menor deve ser dada à U\%, com correlação de 0,2071. Para essa espécie, conforme LORENZI (1992), a germinação é rápida e abundante, não sendo necessária a aplicação de nenhum tratamento para aumento na percentagem daquela variável.
A percentagem de germinação de plântulas normais de $\boldsymbol{E}$. contortisiliquum é positivamente associada à pureza dos lotes e à sua umidade (Tabela 2) e com efeito direto de mesmo sinal e magnitude para a U\% e sinal diferente para a PUR, mas com efeito indireto da PUR via U\% apresentando-se positivo (Tabela 4). Isto indica que um bom preparo nos lotes, com a retirada das impurezas e a manutenção da umidade em níveis adequados, durante o armazenamento, irá favorecer o aumento na taxa de germinação da espécie, bem como na sua manutenção durante o processo de armazenamento, prática desejável em todo tipo de banco de sementes. Tanto para E. contortisiliquum, quanto para A. leiocarpa, para uma elevada percentagem de germinação das plântulas normais, é necessário que estas apresentem alta umidade, ou seja, que possuam alto teor de água, conforme descrito por LORENZI (1992).

O determinante para aumentar a percentagem de germinação das sementes de $\boldsymbol{L}$. pacari baseia-se na associação de algumas características dos lotes, visto que estas explicaram 95,3\% da germinação das sementes. Recomenda-se uma melhoria na 
Tabela 4 - Efeitos diretos e indiretos da pureza dos lotes (PUR), do peso de mil sementes (PMS), da umidade (U\%), da percentagem de plântulas anormais (PA), da percentagem de sementes firmes (SF) e da percentagem de sementes mortas (SM) sobre a percentagem de germinação das plântulas normais (PN), em espécies florestais nativas do Rio Grande do Sul. Santa Maria - RS, 2005.

\begin{tabular}{|c|c|c|c|c|c|c|c|}
\hline \multicolumn{2}{|l|}{ Efeitos } & PUR & PMS & U\% & SF & PA & SM \\
\hline & \multicolumn{7}{|c|}{ - } \\
\hline \multicolumn{2}{|l|}{ Direto } & $-0,021$ & $-0,164$ & 0,415 & --- & --- & --- \\
\hline Indireto via & PUR & --- & $-0,004$ & $-0,008$ & --- & --- & --- \\
\hline Indireto via & PMS & $-0,030$ & --- & $-0,023$ & --- & --- & --- \\
\hline Indireto via & U\% & 0,165 & 0,058 & --- & --- & --- & --- \\
\hline \multicolumn{4}{|c|}{ Coeficiente de determinação } & \multicolumn{3}{|l|}{0,404} & \\
\hline & & - & $--L a f o e$ & Iri------ & ---- & ----- & \\
\hline \multicolumn{2}{|l|}{ Direto } & $-0,165$ & 0,213 & $-0,213$ & $-0,165$ & --- & $-0,713$ \\
\hline Indireto via & PUR & --- & 0,047 & 0,101 & $-0,013$ & --- & $-0,052$ \\
\hline Indireto via & PMS & $-0,06$ & --- & 0,134 & $-0,105$ & --- & $-0,043$ \\
\hline Indireto via & U\% & 0,130 & $-0,134$ & --- & $-0,013$ & --- & $-0,151$ \\
\hline Indireto via & PPM & $-0,013$ & 0,081 & $-0,010$ & --- & --- & 0,011 \\
\hline Indireto via & SM & $-0,228$ & 0,145 & $-0,508$ & 0,049 & --- & --- \\
\hline \multicolumn{4}{|c|}{ Coeficiente de determinação } & \multicolumn{3}{|l|}{0,953} & \\
\hline & & & Pelthop & ubium -- & $-----\cdot$ & -----. & \\
\hline \multicolumn{2}{|l|}{ Direto } & $-0,044$ & 0,949 & 0,096 & --- & --- & -- \\
\hline Indireto via & PUR & --- & 0,005 & $-0,017$ & --- & --- & --- \\
\hline Indireto via & PMS & $-0,111$ & --- & $-0,264$ & --- & --- & --- \\
\hline Indireto via & $\mathrm{U} \%$ & 0,038 & $-0,027$ & --- & --- & --- & --- \\
\hline \multicolumn{4}{|c|}{ Coeficiente de determinação } & \multicolumn{3}{|l|}{0,867} & \\
\hline & & & $-----S c h$ & --- & --- & $-\cdots$ & \\
\hline \multicolumn{2}{|l|}{ Direto } & 0,017 & $-0,298$ & $-0,135$ & --- & --- & $-0,889$ \\
\hline Indireto via & PUR & --- & 0,010 & $-0,003$ & --- & --- & $-0,004$ \\
\hline Indireto via & PMS & $-0,188$ & --- & 0,084 & -- & --- & 0,214 \\
\hline Indireto via & $\mathrm{U} \%$ & 0,023 & 0,038 & --- & --- & --- & $-0,050$ \\
\hline Indireto via & SM & 0,250 & 0,640 & $-0,330$ & --- & --- & -- \\
\hline \multicolumn{4}{|c|}{ Coeficiente de determinação } & 0,585 & & & \\
\hline
\end{tabular}

qualidade dos lotes via manejo de sementes. A percentagem de sementes mortas foi a variável que mais afetou a qualidade dos lotes, pois tanto o efeito direto $(-0,713)$, apresentado na tabela 4 , quanto a correlação $(-0,9493)$, observada na tabela 2 , foram negativos e com magnitudes semelhantes. Considerando que uma das causas mais comuns para tal é a presença de microorganismos, favorecida pela presença de impurezas, esta associação reduz a PN. Desta forma, aumentando a PUR há uma tendência de aumento na PN via aumento do PMS e redução da SM.

A germinação de plântulas normais para a espécie $\boldsymbol{P}$. dubium é altamente dependente do tamanho das sementes, o que é comprovado pelo coeficiente de correlação alto, positivo e significativo $(r=0,9276)$ (Tabela 2) e pelo efeito direto de mesma magnitude e sinal $(0,949)$, conforme apresentado na tabela 4, entre PMS e PN. Assim, para garantir uma boa germinação, é necessário selecionar sementes de maior tamanho. Já a correlação negativa entre as variáveis PUR e U\% sobre PN é devida ao efeito indireto negativo do PMS em ambas as variáveis, comprovando a grande associação do peso das sementes com a sua germinação nessa espécie.

Para o gênero Schinus sp., observou-se que o coeficiente de correlação apresenta mesmo sinal e magnitude que o efeito direto do SM sobre a PN, indicando que, quanto menor o SM maior é a PN, mostrando o mesmo comportamento observado para L. pacari. A relação negativa entre $\mathrm{PN}$ e a U\% das sementes mostra que as sementes armazenadas em ambientes mais úmidos tendem a reduzir a percentagem de germinação, confirmando a importância dessa variável no armazenamento de sementes florestais. HARTMANN \& KESTER (1974) consideram que as condições efetivas para o armazenamento compreendem uma combinação de umidade relativa de 10 a $50 \%$ e uma temperatura de 0 a $10^{\circ} \mathrm{C}$. O teor de umidade das sementes é função da umidade relativa do ar ao seu redor, o que, por sua vez, é influenciado pela temperatura de armazenamento. Para sementes de coníferas, um teor de umidade entre 5 e $8 \%$ tem se 
mostrado efetivo (WANG, 1977). Os teores de umidade para conservação de sementes de diferentes espécies, pelo período de 1 ano, variam de aproximadamente 11 a 14\%, de acordo com TOLEDO \& MARCOS FILHO (1977), verificando-se uma redução da percentagem de plântulas normais à medida que aumenta o teor de umidade das sementes. Já o PMS apresentou magnitude e sinal distintos entre o coeficiente de Pearson e o efeito direto, evidenciando o efeito depreciativo da SM, pois foi a variável que apresentou o maior efeito indireto $(0,640)$ (Tabela 4).

\section{CONCLUSÕES}

As determinações usuais obtidas nas análises de sementes de espécies florestais nativas do Rio Grande do Sul têm relações distintas sobre a germinação das sementes, variando entre as espécies analisadas. As variáveis de maiores relevâncias e associações significativas com a percentagem de germinação de plântulas normais foram o peso de mil sementes, a umidade de armazenamento dos lotes e a percentagem de sementes mortas.

\section{AGRADECIMENTOS}

Ao Centro de Pesquisas Florestais e Conservação do Solo da Fundação Estadual de Pesquisa Agropecuária FEPAGRO, pela disponibilidade dos dados para a realização do trabalho. Ao CNPq, à CAPES e à FAPERGS, pelas bolsas de produtividade em pesquisa e pelo auxílio financeiro.

\section{REFERÊNCIAS}

BRASIL. Ministério da Agricultura e Reforma Agrária. Secretaria Nacional de Defesa Agropecuária. Departamento Nacional de Defesa Vegetal. (1992). Regras para análise de sementes. Brasília, 1992. 365p

CARVALHO, C.G.P. et al. Análise de trilha sob multicolinearidade em pimentão. Pesquisa Agropecuária Brasileira, Brasília, v.34, n.4, p.603-613, 1999.

CARVALHO, C.G.P. et al. Correlações e análise de trilha em linhagens de soja semeadas em diferentes épocas. Pesquisa Agropecuária Brasileira, Brasília, v.37, n.3, p.311-320, 2002.

CRUZ, C.D. Programa GENES, versão windows: aplicativo computacional em genética e estatística. Viçosa: UFV, 2001. 648p.
CRUZ, C.D.; REGAZZI, A.J. Modelos biométricos aplicados ao melhoramento genético. Viçosa: UFV, 1994. 390p.

FLORIANO, E.P. Germinação e dormência de sementes florestais. Santa Rosa: ANORGS, 2004. 19p.

FOWLER, J.A.P.; BIANCHETTI, A. Dormência em sementes florestais. Colombo: EMBRAPA-Florestas, 2000. 23p. (doc.40).

GOEDERT, C. et al. Germoplasma: o que é isso? Seednews. Pelotas, v.9, n.3, p.16-21, 2002.

HARTMAnN, H.T; KESTER, D.E. Propagacion de las plantas. México: Continental, 1974. 810p.

KRAMER, P.J.; KOZLOWSKI, T. Fisiologia das árvores. Lisboa: Fundação Calouste Gulbenkian, 1972. 745p.

LORENZI, H. Árvores brasileiras: manual de identificação e cultivo de plantas arbóreas nativas do Brasil. Nova Odessa: Plantarum, 1992. 368p.

LÚCIO, A.D. Erro experimental relacionado às características dos ensaios nacionais de competição de cultivares. 1999. 73f. Tese (Doutorado em Agronomia) Faculdade de Ciências Agrárias e Veterinárias Campus de Jaboticabal, Jaboticabal.

MACHADO, C.F. Metodologia para a condução do teste de germinação e utilização de raios- $X$ para a avaliação da qualidade de sementes de aroeira-branca (Lithraea molleoides (Vell.) Engl. 2002. 86f. Dissertação (Mestrado em Agronomia) - USP/ESALQ, Piracicaba.

MONTGOMERY, D.C.; PECK, E.A. Introduction to linear regression analysis. New York: John Wiley \& Sons, 1981. 504p.

NASCIMENTO FILHO, F.J. et al. Análise de caminhamento em mudas de guaraná. Pesquisa Agropecuária Brasileira, Brasília, v.28, n.4, p.447-452, 1993.

TOLEDO, F.F.; MARCOS FILHO, J. Manual de sementes: tecnologia da produção. São Paulo: Agronômica Ceres, 1977. $224 p$.

VENCOVSKY, R.; BARRIGA, P. Genética biométrica no fitomelhoramento. Ribeirão Preto: Revista Brasileira de Genética, 1992. 496p.

VIEIRA R.D.; CARVALHO N.M. Teste de vigor em sementes. Jaboticabal: FUNEP, 1994. 164p.

WANG, B.S.P. Procurement, handling and storage of tree seed for genetic research. Canberra: World Consulta Tion on Tree Breeding, 3, 1977. 548p. 